\title{
Mapeando alguns conhecimentos matemáticos incorporados no "esquadro móvel" de Ottavio Fabri (1544-1612)
}

Mapping some mathematical knowledge embodied in Ottavio Fabri's (1544-1612) "mobile square"

Andressa Cesana ${ }^{1}$

Fumikazu Saito ${ }^{2}$

\section{Resumo}

Este artigo apresenta os primeiros resultados de um estudo preliminar sobre a construção e o uso de um antigo instrumento matemático. Nele, realiza-se um mapeamento de conhecimentos matemáticos incorporados no instrumento "esquadro móvel", descrito no tratado L'uso della squadra mobile de Ottavio Fabri (1615) com o intuito de, posteriormente, elaborar uma atividade didática na interface entre história e ensino de matemática. Por meio de uma situação de medição, busca-se aqui demonstrar que as partes do instrumento sintetizam conceitos e que o braço móvel estabelece relações entre esses conceitos. 0 artigo conclui que o "esquadro móvel" apresenta elementos com os quais é possível compor um conjunto de ações para ensinar matemática e, desse modo, aponta para algumas potencialidades didáticas deste instrumento. Este estudo tem por base um documento original e recentes estudos em história da ciência e da matemática. O documento foi analisado contemplando três esferas de análise, a saber, historiográfica, epistemológica e contextual. A análise histórica buscou privilegiar alguns aspectos epistemológicos com a intenção de construir interfaces entre história e ensino de matemática conforme recentes estudos relacionados à incorporação de questões históricas no âmbito do ensino e da aprendizagem de matemática.

Palavras chave: Mapeamento; Instrumento de medida; Conceitos matemáticos sintetizados; Interface.

\section{Abstract}

This paper presents the first results of a preliminary study on the construction and use of an old mathematical instrument. It maps the mathematical knowledge embodied in the instrument named "mobile square" which was described in the treatise L'uso della squadra mobile by Ottavio Fabri (1615) in order to develop later a didactic activity in the interface between history and math teaching. Through a measurement situation, the aim here is to demonstrate that the parts of the instrument synthesize concepts, and that the mobile arm establishes relationships between those very concepts in a measurement situation. It

\footnotetext{
${ }^{1}$ Universidade Federal do Espírito Santo | andressacesana@hotmail.com

2 Pontifícia Universidade Católica de São Paulo | fsaito@pucsp.br
} 
concludes that the "mobile square" has elements that allow composing a set of actions to teach mathematics and, thus, the mapping points to some didactic potentialities of this instrument. This study is based on an original document and recent studies in the history of science and mathematics. The document was analyzed covering three spheres of analysis, namely, historiographic, epistemological, and contextual. The historical analysis sought to privilege some epistemological aspects with the intention of building interfaces between history and math teaching, according to recent studies related to the incorporation of historical questions in the scope of teaching and learning mathematics.

Keywords: Maping; Measuring instruments; Syntetized math concepts; Interface.

\section{Introdução}

Neste artigo, apresentamos os primeiros resultados de um estudo preliminar sobre a construção e o uso de um instrumento denominado "esquadro móvel" ou zoppa, que foi descrito no tratado intitulado L'uso della squadra mobile 3 , publicado pela primeira vez em Veneza, em 1598, por Ottavio Fabri (1544-1612) ${ }^{4}$. Esse tratado e o instrumento nele descrito trazem muitos elementos que podem se afigurar como potencial recurso para a elaboração de propostas didáticas que contemplem a formação de conceitos matemáticos. Assim, com o objetivo de futuramente elaborar atividades ${ }^{5}$ para a formação de professores de matemática (inicial ou continuada), neste estudo mapeamos alguns conhecimentos que se encontram incorporados no esquadro móvel, seguindo de perto as orientações de Saito e Dias (2011, 2013) e de Saito e Pereira (2019).

O mapeamento dos conhecimentos incorporados no esquadro móvel constitui-se como uma etapa da construção de interface entre história e ensino de matemática proposta por Saito e Dias (2013) $)^{6}$. Esse mapeamento deve considerar as condições de produção de saber de uma época e, para tanto, o instrumento e o tratado que versa sobre sua construção e uso não podem ser dissociados, uma vez que é, por meio do tratado, que temos acesso aos conhecimentos e aos procedimentos do saber-fazer matemático de uma época. ${ }^{7}$ Contudo, para atender aos propósitos voltados para o ensino, esses conhecimentos e procedimentos devem ser abordados no seu processo de construção de tal modo a flagrar nele a formação dos conceitos que se encontram sintetizados no instrumento. Desse modo, como observam Dias e Saito (2014), embora o tratado e o instrumento não possam ser entendidos como material e recurso didáticos no sentido que hoje compreendemos,

\footnotetext{
${ }^{3}$ O uso do esquadro móvel.

4 É provável que Ottavio Fabri tenha nascido entre 1544 e 1545, e falecido, abruptamente, nos primeiros meses de 1612 em Veneza. Sobre a vida e estudo sobre Fabri, vide Panepinto $(2008,2009)$ e Cesana (2013).

${ }^{5}$ A elaboração, aplicação e análise de uma atividade de ensino utilizando o esquadro móvel serão realizadas em etapas futuras.

${ }^{6}$ Neste caso, a construção de interface é compreendida pela "constituição de um conjunto de ações e produções que promova a reflexão sobre o processo histórico da construção do conhecimento matemático para elaborar atividades didáticas que busquem articular história e ensino de matemática" (SAITO; DIAS, 2013, p. 22-

23). Sobre o mapeamento dos conhecimentos incorporados no instrumento e outas questões teóricas relativas à construção de interfaces, vide: Saito (2016b, 2016c, 2019).

${ }^{7}$ Em outros termos, é necessário realizar um estudo histórico do instrumento e do tratado. Por exceder os objetivos deste trabalho, não apresentamos aqui a parte histórica, que pode ser consultada em Cesana (2013).
} 
eles podem "fornecer elementos com os quais é possível compor um conjunto de ações voltado para o ensino de matemática" (DIAS; SAITO, 2014, p. 1239). De acordo com Dias e Saito (2014, p. 1239), "as potencialidades didáticas, dessa maneira, devem emergir do movimento do pensamento no processo de apropriação do conhecimento incorporado não só no instrumento, mas também no tratado".

Tendo isso em vista, neste artigo, orientamos a nossa análise para as partes do esquadro móvel, com o propósito de compreender a composição do instrumento. Para tanto, discorremos sobre os conceitos sintetizados nas suas partes e apontamos para os conhecimentos que devem ser mobilizados para construí-lo e utilizá-lo com o intuito de, posteriormente, elaborar com ele atividades na interface entre história e ensino de matemática.

Este artigo encontra-se organizado em três partes. Na primeira, apresentamos o tratado e suas partes. Na segunda, dissertamos sobre a construção do instrumento, suas partes e os conceitos que se encontram nelas sintetizados. Na terceira, por meio de uma situação de medição, revelamos alguns elementos ligados à construção do conhecimento.

\section{O tratado e suas partes}

L'uso della squadra mobile encontra-se organizada em três partes, além da parte inicial, que é dedicada à apresentação da obra, de sonetos em homenagem a Fabri (1615) e, às três cartas dedicatórias de Fabri (1615), ao Senhor Marco Antonio Gandino, ao Senhor Currio Boldieri e ao leitor. As outras três partes apresentam: 1) algumas noções gerais sobre a geometria e os conhecimentos necessários para realizar uma medição; 2) instruções sobre a construção do esquadro móvel passo a passo; e 3) procedimentos para realizar medições em diferentes situações.

Na primeira parte, intitulada "Raciocínio de algumas coisas que você precisa saber antes das medidas geométricas segundo a opinião de bons autores" ${ }^{\prime \prime}$, Fabri (1615) introduz algumas noções básicas ligadas à geometria em geral e à medição em particular, de modo a preparar o leitor para as duas partes subsequentes. Nessa parte, Fabri (1615, p.8r, tradução nossa) define que: "Geometria (...) é uma ciência das grandezas e das formas, no que diz respeito à grandeza que esta ciência é contemplada (...)" e observa que, etimologicamente, o seu significado tem raízes gregas, pois o termo " $\eta \eta$, em grego, significa Terra, em italiano vulgar, e $\mu \dot{t} \tau$ pov, medida: de onde Geometria quase [significa] medida da Terra".

Notemos que a geometria é aqui definida num sentido muito próximo ao de agrimensura. Isso porque a prática da geometria (practica geometriae) estava estreitamente associada, naquela época, à arte de medir terras e terrenos, de modo que era, geralmente, traduzida para o latim pelo termo agrimensura, isto é, a medida (mensura, ae) dos campos (agri, orum $)^{9}$

A estreita relação entre agrimensura e geometria é aqui enfatizada por Fabri (1615) por meio de uma breve história da matemática em que apresenta as principais contribuições dadas pelos antigos egípcios e de alguns estudiosos gregos à geometria, destacando que

\footnotetext{
${ }^{8}$ Ragionamento d'alcune cosi Che si debbono sapere innanzi alle misure Geometriche secondo l'opinione di buoni Auttori.

${ }^{9}$ A esse respeito, consulte Saito $(2015,2018)$.
} 
fora Euclides que teria reunido todas essas contribuições em Elementos (FABRI, 1615). Por meio dessa breve narrativa, o autor quer evidenciar, inicialmente, que a geometria em sua origem tinha o propósito de medir terras (de onde, portanto, recebera seu nome) de tal modo que se reduzia a um conjunto de conhecimentos meramente prático. Contudo, observa, posteriormente, que outros estudiosos passaram a investigar diligentemente seus fundamentos, notoriamente Euclides, que o teria sistematizado, promovendo-o a um corpo de conhecimentos teórico. Assim, a geometria enquanto gênero de conhecimento, desdobrava-se em duas espécies (spetie), uma teórica e outra prática. Segundo Fabri (1615, p. 8v, tradução nossa):

A teórica é aquela que, só com a especulação do intelecto, visa a quantidade, a proporção e a sua medida. E a Prática é aquela outra que se faz evidente com a experiência do sentido, medindo a quantidade de qualquer coisa que não era conhecida anteriormente.

Diferentemente da geometria teórica, que se ocupava com os princípios e as demonstrações ligadas à medição, a prática tinha em vista encontrar a medida das grandezas geométricas segundo seu comprimento, largura e profundidade, estabelecendo, assim, estreita conexão com a agrimensura. Desse modo, Fabri (1615) divide a geometria prática em três partes, segundo as três maneiras de medir (maniere del misurare) mais utilizadas, a saber, Altimetria (Altimetria), Planimetria (Planimetria) e Estereometria (Stereometria). Segundo Fabri (1615, p. 9r, tradução nossa):

A Altimetria trata da medida de uma quantidade segundo uma só divisão, somente segundo seu comprimento. A Planimetria, em seguida, lida com as medidas de quantidade segundo o comprimento e a largura.E a Estereometria, com as medidas de quantidade segundo comprimento, largura e profundidade [...].

A expressão "medida de quantidade" designa a medida de qualquer uma das três grandezas, a saber: comprimento, área e volume. Fabri (1615, p. 9r, tradução nossa) afirma que: "Com a primeira maneira [i.e. a Altimetria] nós medimos o comprimento da linha, com a segunda [i.e. a Planimetria], as medidas da superfície e com a terceira [i.e. a Estereometria], as medidas dos corpos". Em outros termos, as três partes da geometria prática, a Altimetria, a Planimetria e a Estereometria, instruem-nos sobre os modos de obter a medida do comprimento de um segmento, da área de uma superfície e do volume de um sólido, respectivamente. Assim, para obter a "medida de uma quantidade", orienta para:

encontrar quantas quantidades conhecidas (quantità famosa) são nela inseridas, ou quantas partes ela é de uma quantidade conhecida. Mas as quantidades conhecidas (famose quantità) são aquelas que são tomadas de cada uma das muitas conhecidas, como o dedo, o palmo, o pé, o côvado, o passo, a vara, o estádio, a milha, a légua e outras similares (FABRI, 1625, p. 9r, tradução nossa).

Medir, portanto, é encontrar a quantidade que representa o número de vezes que uma "quantidade conhecida" (quantità famosa), isto é, uma unidade de medida, cabe dentro daquilo que se deseja medir. Fabri (1615) recomenda, assim, utilizar cada uma das muitas "quantidades conhecidas" (quantità famose), bastante disseminadas desde a antiguidade, tais como o dedo, o palmo, o pé etc., para expressar a medida de uma grandeza. 
Desse modo, observando que a "quantidade conhecida" (quantità famosa) é a menor medida usada, Fabri (1615) esclarece o leitor que é a partir dessa unidade de medida que as outras, utilizadas em diferentes locais, podem ser convertidas. Apresenta, assim, nas páginas subsequentes, uma descrição detalhada de cada unidade de medida encontrada em diferentes regiões, tais como Roma, França, Urbino, Florença, Servia, Pesaro, Ferrara, Modena, Mantua, Milão, Veneza, Trivigi, Pádua, Vicenza, Verona, Cologna, Rovigo, Badia, Friuli, Bréscia e Bérgamo. Numa época em que não existia ainda uma unidade de medida padrão, o recurso em reduzir as diferentes unidades de medidas encontradas em diferentes locais às "quantidades conhecidas" (quantità famose) era muito útil, pois possibilitava converter as medidas encontradas em diferentes regiões.

Tendo esclarecido que a geometria prática é a parte da geometria que mede "a quantidade de qualquer coisa" (FABRI, 1615, p. 8v) e que a "medida de uma quantidade" é o número de vezes que a "quantidade conhecida" (quantità famosa) cabe dentro daquilo que se quer medir (isto é, comprimento de um segmento, da área de uma superfície e do volume de um sólido), o autor afirma que a Altimetria se divide, portanto, em três partes: "Uma das quais trata das medidas das alturas apenas segundo o seu comprimento. A outra, das medidas dos planos apenas segundo seu comprimento e, a terceira, das medidas de profundidade" (FABRI, 1615, p. 9r, tradução nossa). E observa que essas três partes compartilham dos mesmos princípios geométricos e tem por base o triângulo retângulo e suas propriedades.

Cabe aqui observar que Fabri (1615) se insere na antiga tradição dos agrimensores e arquitetos medievais, que utilizavam triângulos retângulos para solucionarem problemas relacionados à medição de distância, altura e profundidade ${ }^{10}$. Porém, diferentemente dela, introduz o uso dos ângulos, estabelecendo a relação entre os ângulos e os lados do triângulo retângulo para realizar a medição. Contudo, é preciso considerar que ele não recorre a conhecimentos trigonométricos, tal como eram comuns em tratados dedicados à astronomia e à arte da navegação" ${ }^{11}$. O uso do ângulo e a sua relação com o lado está relacionado aos conhecimentos de óptica (notoriamente euclidiana) que estavam na base das teorias de perspectiva bastante disseminadas em território italiano naquela época. ${ }^{12}$

De fato, Fabri (1615, 9v, tradução nossa) afirma que a vista "apreende sob um certo ângulo agudo a quantidade da coisa visível tomada pela base, e quanto mais agudo ele for, tanto menor e perceptível será a quantidade" de tal modo que "A um ângulo menor corresponde a uma base menor" e, desse modo, a uma altura menor conforme a Figura 1. Assim, segundo Fabri (1615, 10r, tradução nossa),

toda altura a ser medida num espaço, ou mesmo profundidade, é sempre tomada como uma linha reta (...) e sempre altura faz um ângulo reto no espaço, isto é, $C$ (...) e a qualquer momento, eu conheço sob o ângulo $B$ [o lado] CA, e (...) sob o ângulo $A$, eu sei [o lado] BC e, assim, de acordo com a pequenez desses dois ângulos agudos, A e B, [e conheço] se a coisa (i.e., o lado) é maior ou menor (...).

\footnotetext{
${ }^{10}$ A esse respeito, consulte: Hugo de San Vitor (1991) e Villard de Honnecourt(1858); vide também estudos de Saito (2016a).

${ }^{11}$ Por exceder os objetivos deste trabalho, não discorreremos aqui sobre a relação entre a astronomia, navegação e agrimensura, a esse respeito, vide Bennett $(1991,1998)$.

${ }^{12}$ Consulte Euclides (1996), vide também Camerota (1998).
} 


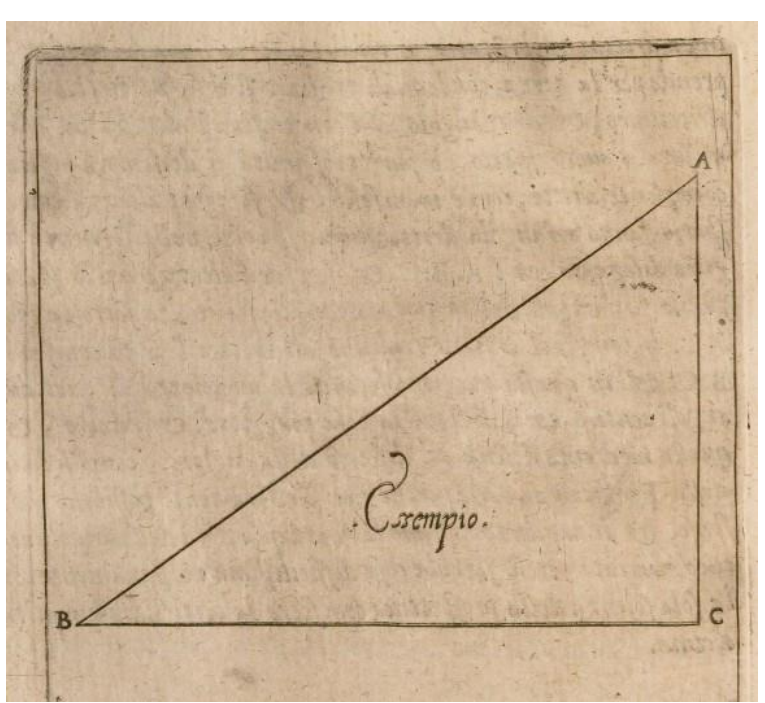

Figura 1: A relação entre ângulo e base Fonte: Fabri (1615, 10v).

Nesse exemplo, Fabri (1615) explica que o olho, estando em B, abarca a altura AC sob o ângulo $\mathrm{A} \widehat{\mathrm{BC}}$. Considera, entretanto, que o segmento $\overline{\mathrm{AC}}$ é perpendicular ao raio de visão dado pelo segmento $\overline{\mathrm{BC}}$ e que, uma vez formado o triângulo retângulo $\mathrm{ABC}$, o outro raio de visão dado pelo segmento $\overline{\mathrm{BA}}$, define outro ângulo agudo $\widehat{\mathrm{A}}$, a partir do qual é possível conhecer a medida do segmento $\overline{\mathrm{BC}}$, pois, de acordo com o estudo da perspectiva (prospettiva) baseado na Óptica de Euclides, o lado maior do triângulo retângulo correspondia ao ângulo maior e vice-versa. ${ }^{13}$ Desse modo, aplicado à arte de medir, o autor observa que os antigos mensuradores de coisas (misuratori delle cose) encontraram, por meio de instrumentos artificiais (stromenti artificiali), a verdadeira medida das grandezas. E que, ao estudar e refletir sobre esses instrumentos, elaborou o esquadro móvel do qual propõe discorrer, neste tratado, sobre a sua construção e uso.

\section{Sobre a construção do esquadro móvel}

A construção do esquadro móvel é tratada na segunda parte, intitulada "Fabricação do instrumento"14. Inicialmente, esclarece que o instrumento pode ser confeccionado em: "[...] papelão, parte em madeira de cipreste, parte em cobre e parte em latão, que a propósito, são os preferidos por mim, na verdade por serem de tão macio metal que me agradaram mais que os outros [...]" (FABRI,1615, p. 15r, tradução nossa). Ele orienta aquele que deseja fabricar o instrumento que o faça de madeira não só por ter baixo custo, mas também por ser um material mais fácil de ser manuseado. Entretanto, sugere a aqueles que querem confeccioná-lo em metal, mas que, contudo, não sabem utilizar corretamente o buril e os compassos para o traçado das linhas, buscar auxílio com algum artesão.

Fabri (1615) tem preferência pela madeira de cipreste, cobre e latão por causa da sua maleabilidade, durabilidade e rigidez. O instrumento deve ser confeccionado com material durável e rígido não só para que fosse resistente ao apodrecimento ou às pragas, mas

\footnotetext{
${ }^{13}$ Vide, por exemplo, Barbaro (1569).

${ }^{14}$ Fabrica dello Istrumento.
} 
também para conferir maior precisão nas medidas, uma vez que teria menos chances de sofrer deformações.

Após a indicar os tipos de materiais possíveis de serem usados na confecção do instrumento, Fabri (1615) passa a descrever as partes do instrumento e, para tanto, fornece uma ilustração do mesmo. Essa descrição é fornecida na Proposta I, da terceira parte do tratado, intitulada O uso da esquadra móvel. Como podemos observar na Figura 2, o esquadro móvel é composto de um braço fixo (braccio stabile), um braço móvel (braccio mobile), um quadrante geométrico com a escala altímetra, um "meio círculo" (mezzo cerchio), quatro miras (pendolettes ou traguardi).

Podemos reconhecer, na composição das partes deste instrumento, diferentes conceitos geométricos que se encontram nele sintetizados. De fato, à primeira vista, o instrumento e suas partes revelam conceitos geométricos bastante elementares, entretanto, oculta as diferentes ações que são requeridas para construí-lo. É somente por um mapeamento desses conceitos, seguindo de perto as orientações fornecidas por Fabri em seu tratado, é que podemos divisar as ações que deverão ser executadas para confeccionar o esquadro móvel. Essas orientações ajudam-nos a compreender como os conceitos se encontram organizados no instrumento e, dessa maneira, revelam, por meio das ações que são solicitadas para sua confecção e uso, alguns elementos potencialmente didáticos a serem explorados no ensino de matemática.

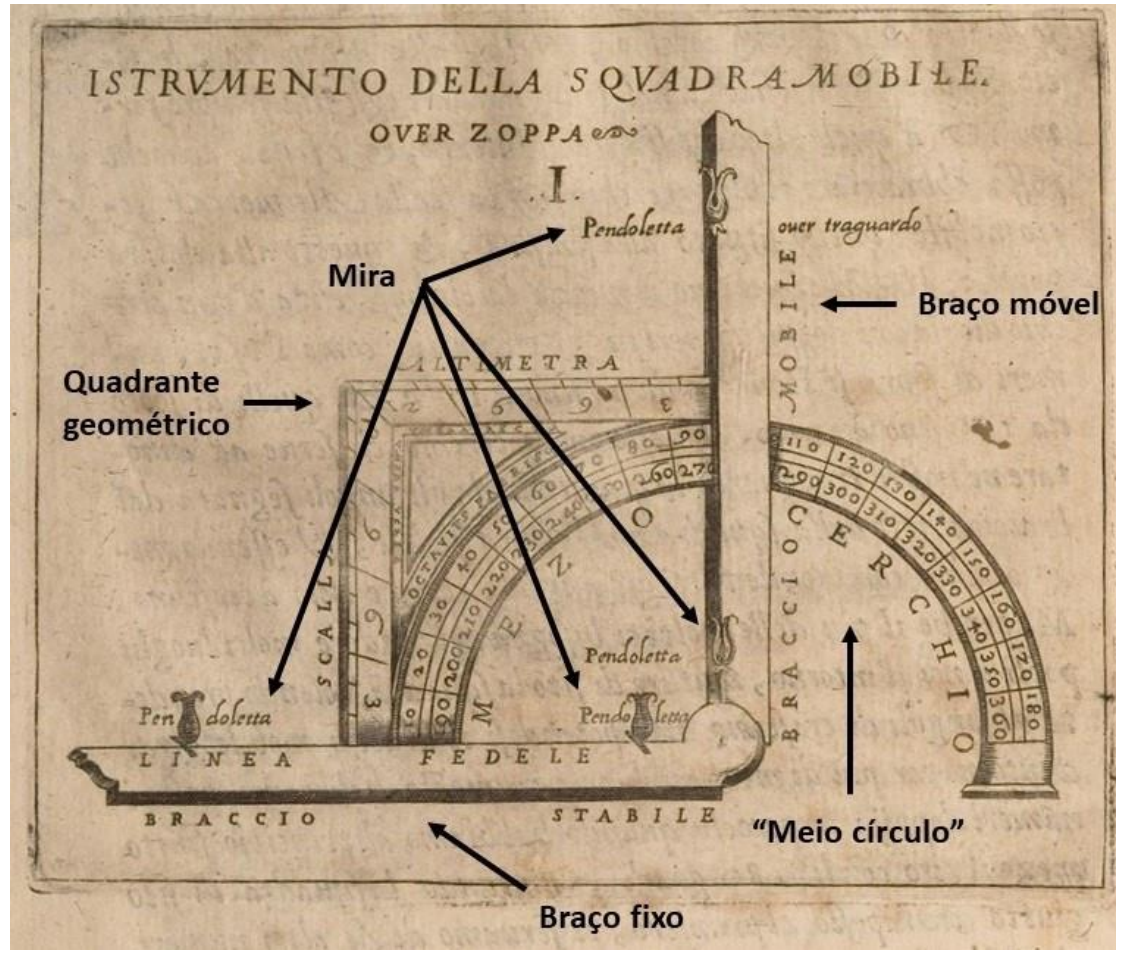

Figura 2. Partes do esquadro móvel em destaque Fonte: Adaptado de Fabri (1615, p. 19r)

No que diz respeito às dimensões e à disposição das partes do instrumento, o autor descreve que os braços fixos e móveis:

são duas pequenas réguas retas, ambas com mais ou menos um palmo [de comprimento], que, de um lado, se juntam, a um círculo (cerchio), cujo diâmetro é o dobro da largura dessas pequenas réguas, de tal modo a passarem pelo centro desse círculo (cerchio), chamado centro do 
esquadro, em torno do qual giram convenientemente a metade de um giro inteiro (FABRI, 1615, p. 18v, tradução nossa).

Se acompanharmos essa descrição juntamente com a ilustração do instrumento, constatamos que ele tem dois braços, um fixo (braccio stabile) e um móvel (mobile) cujos comprimentos coincidem com o raio do círculo (cerchio) do "meio círculo" (mezzo cerchio). Aqui convém observar que o termo mezzo cerchio não designa o semicírculo geométrico. Esse termo se refere a uma parte do instrumento e, mais adiante, define que o "meio círculo" (mezzo cerchio) é a "metade da circunferência de um círculo" (FABRI, 1615, p. 19r, tradução nossa), ou seja, que é uma parte do instrumento que tem as mesmas propriedades geométricas de um semicírculo. Desse modo, os dois braços encontram-se fixados um com outro no centro do círculo (cerchio) que coincide com o centro do "meio círculo" (mezzo cerchio), denominado aqui centro do instrumento. É em torno desse centro que o braço móvel gira de forma conveniente até a metade de um giro completo de circunferência, ou seja, até formar um ângulo de $180^{\circ}$ com o braço fixo.

Ainda sobre esses braços, fixa, em cada um deles, duas miras (pendolettes ou traguardi), que "servem para ver coisas das quais queremos conhecer o lugar e a distância" (FABRI, 1615, p. 18v, tradução nossa). Assim, elas são utilizadas para alinhar o raio visual que permitiria localizar os vértices $C$ e A do triângulo retângulo mencionado na Figura 1, de tal modo que o braço fixo apontasse para o vértice $\mathrm{C}$ e, a móvel encontrasse o ponto $\mathrm{A}$. Desse modo, o braço fixo deverá estar imóvel e preso na parte de baixo do "meio círculo" e da escala altímetra do quadrante geométrico, enquanto, o outro, móvel, deve girar e "cingir o 'meio círculo' e a escala altímetra" (FABRI, 1615, p. 19r, tradução nossa).

O braço móvel, portanto, aponta tanto a escala altímetra do quadrante geométrico, quanto a escala angular do "meio círculo". Esse se encontra dividido em números duplos em 360 partes (...) de tal modo que, segundo Fabri (1615, p. 19r, tradução nossa), "Os números de cima se estendem de 10 a 180 e os de baixo de 190 a 360". E observa que "Esse 'meio círculo' serve aqui para apontar nas nossas miras a quantidade de ângulos marcados pelo braço reto (dritto) esquadra com a linha fiel (linea fedele) e, como é um 'meio círculo', inclui todos os ângulos".

Por braço reto (braccio dritto), Fabri (1615) se refere ao braço móvel que está perpendicular (ou seja, reto) em relação ao braço fixo, que se encontra na direção da linha fiel (linea fidele) conforme a Figura 2. Desse modo, o braço móvel, indica, no "meio círculo", "a quantidade de ângulos", isto é, a medida do ângulo de abertura visual utilizado para abarcar a altura, a distância e a profundidade daquilo que se quer medir. Assim, como o ângulo visual sempre será encontrado num semicírculo, visto que o campo visual nunca excederá $180^{\circ}$.

Entretanto, observa Fabri (1615, p. 19r, tradução nossa) que, às vezes, "temos necessidade de observar muitos lugares ao nosso redor, [e] mudar o alvo do esquadro para capturar os [outros] ângulos". Nesse caso, não seria possível girar o braço móvel para além do "meio círculo". É por esta razão que a sua escala é composta por "números duplos", ou seja, por duas escalas em que a superior se estende de $10^{\circ}$ a $180^{\circ}$ e, a inferior, de $190^{\circ}$ a 360․ Desse modo, Fabri (1615, p. 19r, tradução nossa) observa que: "quando tivermos acabado a metade do giro com 180 graus, mudando o esquadro de lugar, justo contraposto ao primeiro [lugar], usamos os outros números que ascendem até 360 graus, e compreendem um giro inteiro". Em outros termos, a escala inferior (marcada de $190^{\circ}$ a 
$360^{\circ}$ ) é utilizada no caso em que amplitude ultrapasse os $180^{\circ}$, quando duas medições, ou mais, são compostas, como ocorre no caso de mapeamento de terrenos.

Notemos, como mostra a Figura 2, que o "meio círculo" se encontra dividido de $10 \mathrm{em}$ 10 partes. A esse respeito, Fabri (1615, p. 16r, tradução nossa) orienta dividir o "meio círculo" em 18 partes de modo que "cada uma destas pequenas partes esteja distribuída em 10 graus". Entretanto, não fornece instruções de como proceder para realizar essa divisão, nem explica por que razão dividimos o arco em 18 partes.

Do mesmo modo, na construção da escala altímetra, o autor não explicita em detalhes os procedimentos necessários para traçá-la, mas apenas instrui o leitor para construir um quadrante da seguinte maneira:

Divido o lado do quadrado da escala altimétrica da sombra invertida (ombra inversa) em quatro partes e, assim, igualmente, o lado da sombra direita (ombra retta) em quatro partes, e cada uma de suas partes em três partes, e cada uma dessas partes, ou em cinco ou dez [partes], como quisermos (...) e depois a partir do centro do "meio círculo", traço aquelas pequenas linhas que se veem na Figura (FABRI, 1615, p.16v, tradução nossa).

Por sombra invertida (umbra versa) e sombra direita (umbra recta), ele se refere ao lado do quadrante que é perpendicular e paralelo, respectivamente, ao braço fixo (Figura $2)^{15}$. Ele instrui para dividir cada um desses lados em quatro partes e, cada uma delas em três partes que, ainda devem ser divididas em cinco ou dez subpartes. Uma vez divididos, traçamos linhas a partir do centro do "meio círculo" até cada uma das divisões de cada um dos lados do quadrante e, assim,

(...) com números conhecidos, no lado do braço fixo, anoto 3 na primeira divisão (casella), 6 na segunda, 9 na terceira e 12 na última; mas como 12 deve ser o seguinte [número] no ângulo reto do quadrado, faço o doze servir a uma e a outra [escala] e, assim, [anoto] nove, isto é, 9, a seguinte, 6, [e] a outra divisão, que fica acima do "meio círculo" do número 90 da primeira ordem e o número 270 da segunda ordem, [anoto] 3 (...) (FABRI, 1615 , p.16v, tradução nossa).

Ou seja, cada divisão recebe um número, como pode ser visto na Figura 2. Assim, a escala da sombra invertida (ombra inversa) recebe os números 3, 6, 9 e 12 a partir do braço fixo; e, a da sombra direita (ombra retta), a partir da marcação superior do "meio círculo", isto é, onde o braço móvel marcar $90^{\circ}$ (na primeira ordem) ou $270^{\circ}$ (na segunda ordem).

Nessas orientações, Fabri (1615) solicita, em primeiro lugar, dividir um segmento, no caso, o lado de um quadrado, em quatro partes iguais, e depois, subdividi-los em partes menores também iguais. Notemos, entretanto, que ele, em momento algum, instrui como realizar essas divisões, nem explicita o motivo pelo qual o lado deve ser dividido em quatro partes (nem mais nem menos), e nem esclarece a numeração 3, 6, 9 e 12 da escala altímetra.

\footnotetext{
${ }^{15}$ As inscrições em latim, umbra recta e umbra versa, encontradas na ilustração do instrumento, correspondem em toscano antigo a ombra retta e ombra versa respectivamente.
} 
A omissão dos procedimentos para realizar a divisão da circunferência em 18 partes, bem como a da escala altímetra em 4 partes, é indício de que L'uso della squadra mobile não é um manual do tipo "faça você mesmo", visto que, para confeccionar o instrumento, é necessário ter conhecimentos matemáticos. Isso significa que o tratado de Fabri (1615) foi escrito para um público que estava familiarizado com os conhecimentos matemáticos necessários para construir e usar o instrumento. Assim, como esses conhecimentos eram compartilhados pelos artesãos e praticantes de matemáticas, era desnecessário explicitá-los. No entanto, é nesse aspecto que L'uso della squadra mobile é um interessante material a ser explorado na interface entre história e ensino de matemática. A omissão desses procedimentos converte-se em interessantes atividades que potencializam a articulação mental não só dos conceitos envolvidos, como de círculo, circunferência, arcos, polígonos, reta, segmento de reta, mediatriz, etc., mas também dos conhecimentos geométricos que poderiam ser mobilizados para executar essas ações, tais como a construção de polígonos regulares, divisão de arco, divisão de segmentos de reta, entre outros.

Mas, para além do entendimento dos conceitos matemáticos e dos conhecimentos mobilizados para construir o instrumento, é o seu uso para realizar uma medição que revela interessantes elementos ligados à construção do conhecimento. Como abordamos a seguir, os diferentes conceitos matemáticos que se encontram sintetizados na construção do esquadro móvel são mobilizados ao utilizá-lo para realizar uma medição. Assim, ao movermos as partes do instrumento, compreendemos não só a sua disposição, mas também as relações geométricas ali implícitas, revelando, desse modo, os conhecimentos que se encontram nele incorporados.

\section{Sobre o uso do esquadro móvel}

As instruções sobre o uso do esquadro móvel compõem a última parte de L'uso della squadra mobile, na qual Fabri (1615) se refere a diversas situações de medição, organizadas em 22 propostas. Em cada uma dessas propostas, ele apresenta um enunciado de problema e explica como proceder para resolvê-lo.

Para os propósitos deste artigo, apresentamos apenas uma situação de medição, que propõe encontrar a medida da altura de um objeto, contempladas nas Propostas III e IV. Vamos aqui mapear alguns conhecimentos matemáticos que emergem da manipulação do instrumento, procurando evidenciar, pelas ações solicitadas por Fabri (1615), o movimento que fazem os conceitos, que se encontram sintetizados nas partes do instrumento.

A proposta III está assim intitulada: "Encontrar a altura de uma coisa, elevada perpendicularmente sobre um plano, da qual possamos nos aproximar ou distanciar" (FABRI, 1615, p. 22r, tradução nossa). Nessa proposta, o autor orienta que se deve, inicialmente, dispor o esquadro móvel de tal modo que o braço fixo se encontre nivelado e "o braço móvel posicionado em $45^{\circ}$ no meio círculo ou em 12 na ponta [do quadrante]" (FABRI, 1615, p. 22r, tradução nossa), isto é, na ponta em que a umbra recta e umbra versa se encontram. Assim, mantendo fixa essa abertura e usando as miras do braço móvel, o medidor deve posicionar-se em um local que consiga visualizar, com clareza, o cume do objeto, tal como ilustra a Figura 3. 


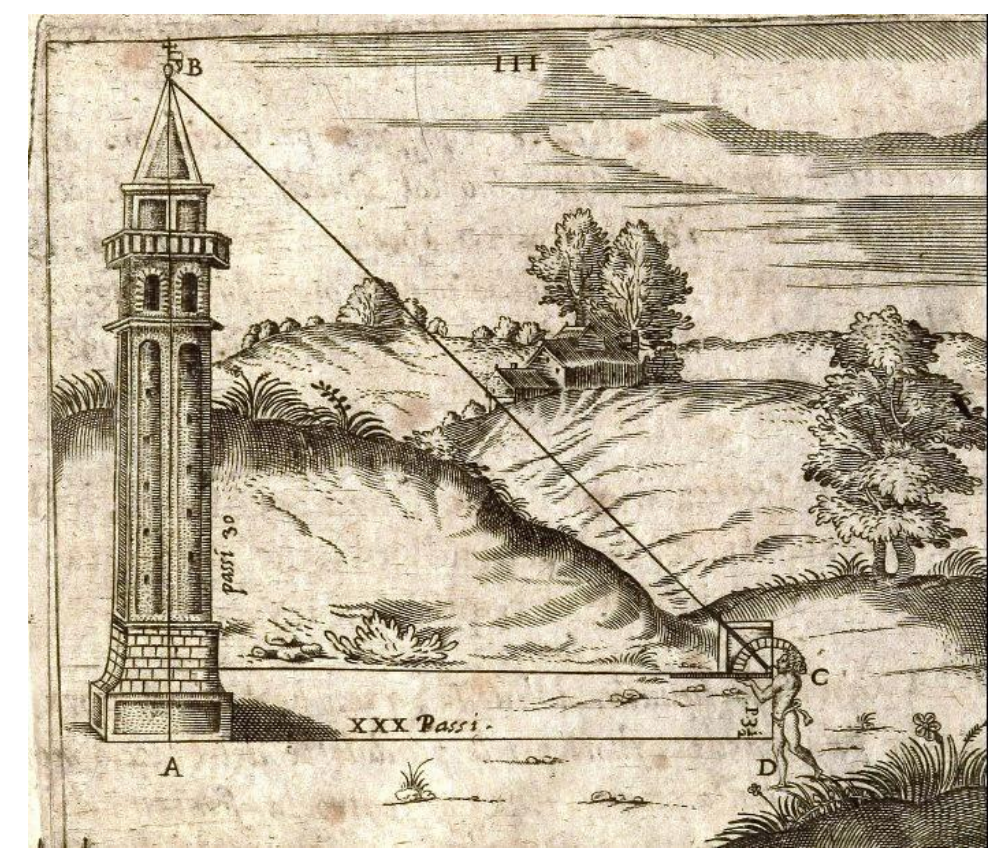

Figura 3: Esquema ilustrativo da Proposta III. Fonte: Fabri (1615, p. 23v).

Fabri (1615) não apresenta, nem dá, claramente, qualquer razão matemática que justifique os passos para desenvolver a solução deste problema. Ele, simplesmente, indica o caminho a seguir. Nesse caso, como podemos perceber pela Figura 3, os conceitos matemáticos que são mobilizados para realizar a medição se encontram sintetizados no quadrante e no "meio círculo" que compõem o esquadro móvel. Assim, ao fixar o braço móvel em $45^{\circ}$ no "meio círculo", que corresponde à marcação 12 da escala altímetra, as partes do esquadro móvel formarão um triângulo retângulo isósceles. Esse mesmo triângulo formado pelas partes do instrumento é semelhante ao triângulo maior que abarca a altura da torre de modo que podemos afirmar que ele também é um triângulo retângulo isósceles.

Desse modo, quando o braço fixo se encontra nivelado e a mira do braço móvel visualiza o cume da torre, é possível inferir que a sua altura corresponde à distância do esquadro ao pé da torre adicionada à altura do centro do instrumento ao plano. Ou seja, em linguagem matemática moderna, que a altura da torre corresponde a $\overline{\mathrm{AB}}=\overline{\mathrm{AD}}+\overline{\mathrm{CD}}$. Portanto, para encontrar a altura da torre, é necessário medir a distância $A D$ e a altura CD, o que é simples de ser executado.

Um caso mais geral do mesmo problema é apresentado na Proposta IV, que é intitulada: "Tomar a altura de uma coisa, que está elevada perpendicularmente sobre um plano, sem que dela se possa aproximar ou distanciar" (FABRI, 1615, p. 24r, tradução nossa).

O primeiro passo para a resolução desse problema é posicionar o esquadro nivelado de tal modo que o cume do objeto seja visto pelas miras do braço móvel, formando, tal como podemos ver na Figura 4, o triângulo ABC ou ABD. Depois, devemos observar o ponto que o braço móvel corta a escala altímetra e também em qual umbra (a recta ou a versa). 


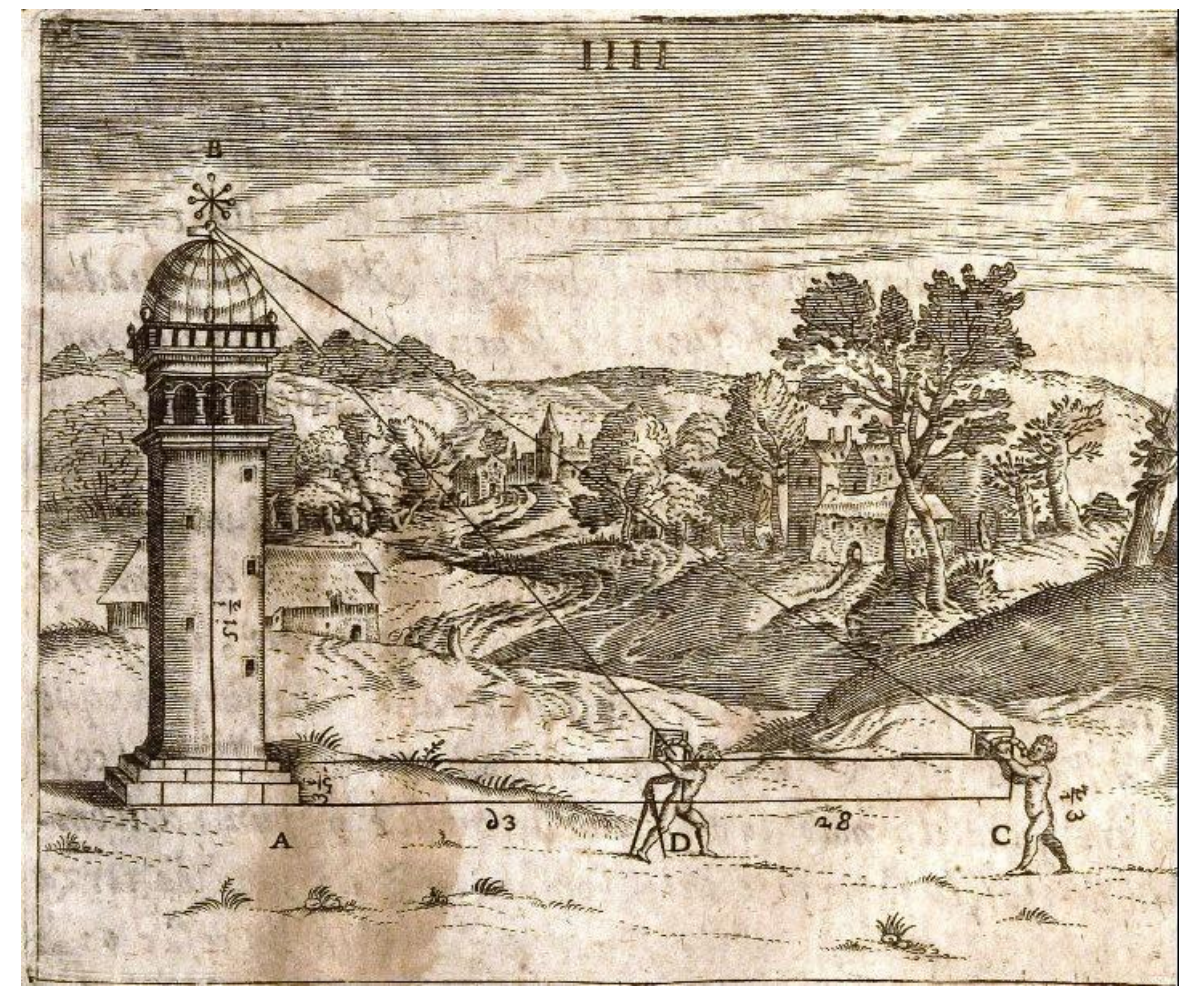

Figura 4: Ilustração da Proposta IV. Fonte: Fabri (1615, p. 25r).

No que se conclui que, segundo o autor, se o braço móvel tocar a umbra recta, deduziremos que a altura do objeto será maior do que a distância do esquadro à base do objeto que se deseja medir. E ainda, que a razão entre o ponto onde o braço móvel corta a escala altímetra e toda a umbra (no caso, 12) será a mesma que a distância do esquadro ao pé do objeto e a altura do mesmo. Isso é retratado na seguinte passagem:

Coloque o esquadro no nível, como foi dito acima [isto é, na Proposta III], depois olhe pelas miras do braço móvel, da circunferência ao centro, o cume do objeto, e observo quantos pontos ele corta na Escala Altimetra com sua linha fiel, e de qual ombra [o braço móvel intersecta]; porque se ele tocar a ombra retta, saberemos que a altura será maior [do] que a distância do esquadro ao seu pé. E os pontos da ombra retta tirados da linha fiel à toda ombra, isto é 12, terão aquela proporção, que terá a distância do esquadro do pé do objeto à altura do mesmo, [...] (FABRI, 1615 , p. 24r, tradução nossa).

Neste caso, diferentemente da proposta anterior, o braço móvel não é fixado de antemão. Depois de nivelar o braço fixo (isto é, fixá-lo na direção da linha fiel), o braço móvel é movido até alcançar o cume da torre, tal como ilustra Figura 4. O braço móvel, dessa maneira, pode cortar a escala altímetra em três regiões: na umbra versa (entre 0 e 12), na ponta (12), na umbra recta (entre 12 e 0), como ilustra a Figura 5.

Ao afirmar que, "se o braço móvel cortar a umbra recta, então a altura do objeto será maior do que a distância do instrumento ao pé do objeto que se deseja medir" (isto é, que a altura $A B$ será maior do que a distância $A C$ ), Fabri (1615) está se referindo a uma propriedade geométrica que é constatada a partir da disposição do braço móvel no momento que o medidor fixa a sua mira (Caso 3 - Figura 5). 

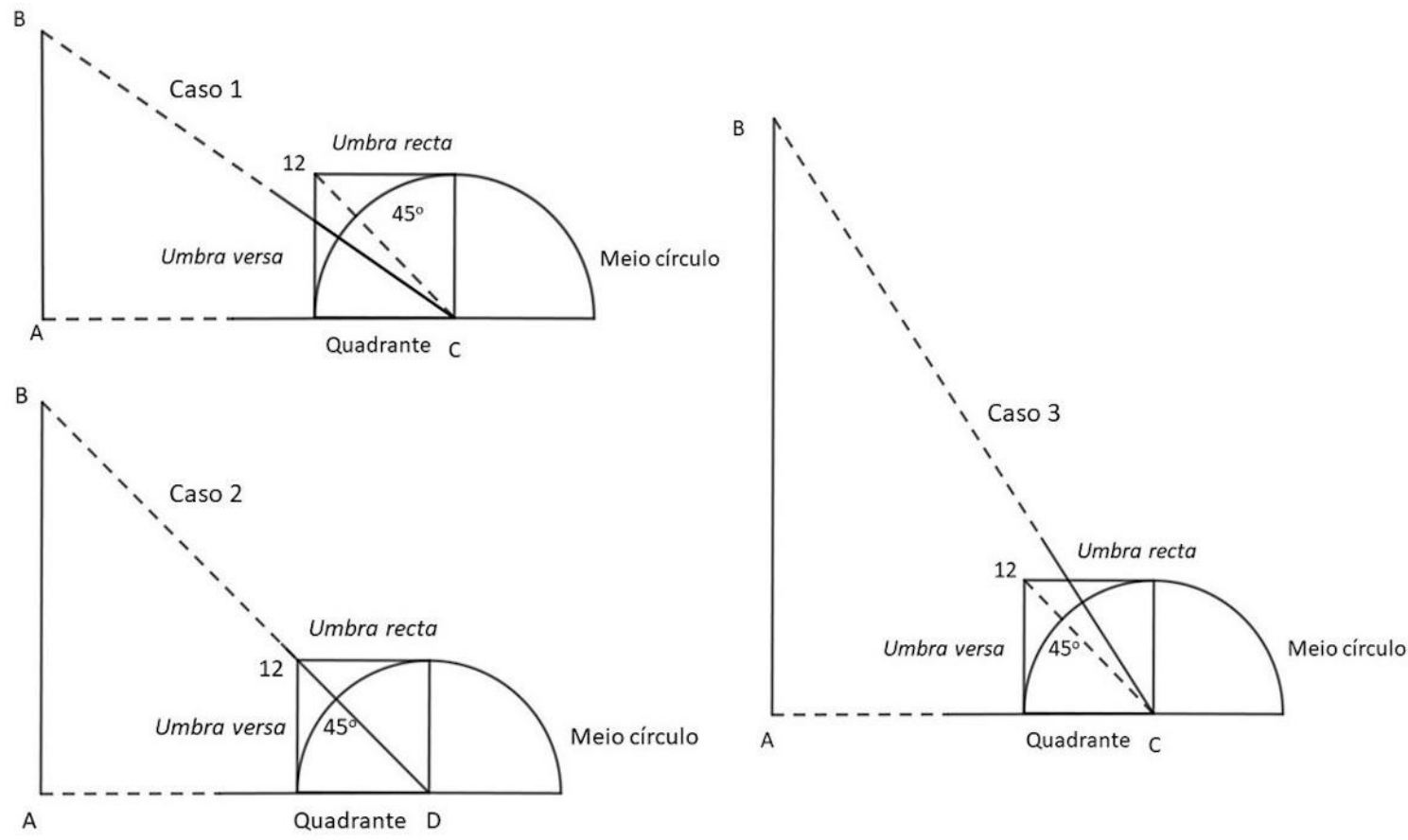

Figura 5: llustração de três possíveis casos. Fonte: Elaborado pelos autores.

Nesse caso, quando o braço móvel intersecta a umbra recta, o ângulo estabelecido com a linha fiel será maior do que 450, o que é indicado pelo "meio círculo". Assim, a disposição dessas partes no esquadro móvel mostra que este ângulo Ĉ será maior do que o ângulo $\widehat{B}$ de tal modo que a altura da torre $A B$ será maior do que a distância $A C$. Isso porque "ao maior ângulo de um triângulo, opõe-se o maior lado". De fato, essa mesma propriedade é constatada também no caso 1, e, o caso 2 refere-se à Proposta III, mencionada anteriormente.

De outro modo, ao garantir que uma proporção se forma entre os lados do esquadro móvel e os lados correspondentes do triângulo formado pelo pé do objeto a ser medido, pelo seu cume e pelo ponto onde está posto o olhar do observador com o instrumento, Fabri (1615) está fazendo alusão à semelhança entre os seguintes triângulos: o triângulo retângulo, que está incorporado no quadrante geométrico que compõe o esquadro móvel, e o triângulo (também retângulo) que é formado pela base do objeto, pelo cume do objeto e pelo centro do esquadro móvel (isto é, o triângulo $A B D$ ou $A B C$, como vemos na Figura 4). Desse modo, para encontrar a medida da altura do objeto, Fabri (1615) solicita resolver a proporção estabelecida acima pela semelhança desses dois triângulos e, ao resultado obtido, adicionar a altura de onde está o esquadro móvel ao plano, tal como instruíra na Proposta III.

No caso em que o braço móvel intersecta a umbra recta, a semelhança estabelecida entre os dois referidos triângulos pode não ser elementar. De fato, observando a Figura 5 (Caso 3), para que a medida da altura do objeto seja obtida, é preciso avaliar os lados homólogos dos dois triângulos: triângulo $A B C$ e o triângulo formado a partir da fixação do braço móvel ao se mirar o cume do objeto, o ponto, é um triângulo em ponta cabeça que se observa no instrumento. Percebemos então que a semelhança se dá porque os dois triângulos têm dois ângulos congruentes: os retos e os alternos internos $A \widehat{B} C$ e aquele formado pelo braço móvel e pelo lado do quadrante que é paralelo à umbra versa. 
Fabri (1615) também explica a situação de o braço móvel cortar a umbra versa. Observa que, nesse caso, a altura do objeto será menor do que a distância do esquadro ao pé do mesmo, isto é, que a altura AB será menor que a distância $A C$ (Caso 1). E, de modo análogo ao anterior, sugere encontrar a medida da altura do objeto desejado estabelecendo a semelhança entre o triângulo formado no esquadro móvel e o triângulo formado pela base do objeto, pelo cume do objeto e pelo centro do esquadro móvel (isto é, o triângulo ABD ou $A B C)$.

\section{Considerações finais}

Neste artigo exploramos apenas uma situação de medição apresentada por Fabri (1615) em duas propostas para mapearmos alguns conhecimentos que se encontram incorporados no esquadro móvel. Como mencionamos, as partes do esquadro móvel sintetizam diferentes conceitos matemáticos, tais como de ângulo, quadrado, semicircunferência, triângulo retângulo, triângulo isósceles, mediatriz, bissetriz, arco, medida, unidade de medida, e outros procedimentos geométricos, como divisão de segmentos, de arco, de circunferência etc. Esses conhecimentos emergem das partes do instrumento cujo movimento, propiciado pelo braço móvel, estabelece relações entre os conceitos sintetizados no quadrante e no "meio círculo", dando, desse modo, significado a outros tantos conhecimentos (e também conceitos) que são solicitados para realizar uma medição, tais como os de proporção entre os lados dos triângulos correspondentes, de semelhança entre triângulos retângulos, e outras propriedades geométricas, como perpendicularidade e paralelismo entre retas, além de relações métricas em triângulos retângulos.

A partir desse mapeamento, observamos alguns elementos com os quais podemos compor certas ações para a elaboração de uma atividade de ensino de matemática, especificamente, de geometria. Uma delas diz respeito, por exemplo, à exploração da relação entre ângulo e o cateto oposto a esse ângulo em um triângulo retângulo propiciada pelo uso das escalas altímetra e do "meio círculo". Ainda nesse particular, é possível elaborar atividades que envolvam a relação entre as propriedades de um quadrado e de um triângulo retângulo, bem como entre arco de circunferência e ângulo, também como explorar as relações de proporção entre os lados de triângulos retângulos e outras relações métricas propiciadas pelo movimento que faz o braço móvel.

No que diz respeito às relações métricas, é ainda possível desenvolver outras atividades que busquem relacionar número, medida e grandeza, considerando-se aqui a relação entre diferentes grandezas, e também a conversão e comparação de medidas entre diferentes grandezas, por exemplo, entre comprimento e ângulo, propiciada pela relação dada pelo braço móvel entre a escala altímetra e a escala angular do "meio círculo". Outro aspecto interessante ainda nessa direção refere-se às questões em torno da noção de unidade de medida. O esquadro móvel não traz nele uma unidade de medida padrão, mas permite estabelecer relações métricas (isto é, proporções entre as partes e subpartes) para qualquer unidade de medida desejada.

Assim, considerando as reflexões feitas sobre sua composição, bem como da situação de medição aqui apresentada, compreendemos que o esquadro móvel se configura como um instrumento potencialmente didático. Desse modo, tanto uma atividade que tenha em vista a sua "reconstrução", quanto o seu uso, pode contribuir para dar significado à formação de alguns conceitos matemáticos. Com efeito, como mencionamos, os 
procedimentos para dividir a escala altímetra e a do "meio círculo" foram omitidos por Fabri (1615). A exploração dos conhecimentos que devem ser mobilizados para realizar essas divisões estabelece novas relações entre os conceitos de ângulo e segmento de reta, bem como pode dar significado às noções de mediatriz e bissetriz por exemplo. Ademais, no que diz respeito ao uso instrumento para obter a medida da altura de objetos, o movimento do braço móvel estabelece outras relações, que integram, por exemplo, os conceitos de triângulo retângulo, semicircunferência, arco, proporcionalidade, perpendicularidade e assim por diante.

O esquadro móvel parece revelar outros aspectos interessantes. Note que, neste estudo, exploramos apenas o caso em que o instrumento é utilizado para medir altura de objetos. Para tanto, o instrumento é posicionado perpendicularmente em relação ao chão (isto é, em termos menos formais, de pé), oportunizando aqui a mobilização das propriedades geométricas e métricas em triângulos retângulos. Entretanto, ele pode também ser utilizado em outra posição, paralelo ao solo (isto é, em termos menos formais "deitado"), para medir distância entre dois objetos dispostos em dois lugares diferentes no plano, revelando, assim, outras relações conceituais propiciadas pelo movimento das partes do instrumento.

Com efeito, como vimos na construção do esquadro móvel, Fabri (1615) observa que o "meio círculo" é composto por duas escalas, uma superior e outra inferior, que são utilizadas de forma justaposta para mapear terrenos, isto é, para encontrar a medida da distância entre dois ou mais lugares no plano. Assim, diferentemente da situação de medição aqui apresentada, que demanda o uso da escala altímetra, (e dispensa, portanto, o uso do "meio círculo"), outras situações solicitam girar o braço móvel para além de 90, formando, assim, triângulos obtusos. E é nessa direção que estamos atualmente orientando nossos esforços, pois o uso "meio círculo" permite estabelecer outras relações conceituais ligadas aos triângulos em geral, não se restringindo apenas às relações métricas e geométricas em triângulos retângulos. Assim, este estudo preliminar nos mostrou que o esquadro móvel pode ainda revelar outros novos elementos na interface entre história e ensino de matemática. Nesse sentido, podemos dizer que o esquadro móvel é um rico instrumento que traz elementos potencialmente didáticos para o ensino de geometria e contribui para o movimento do pensamento e a formação de conceitos.

\section{Referências}

BARBARO, D. La pratica della perspettiva di monsignor Daniel Barbaro. Venetia: Camillo \& Rutilio Borgominieri fratelli, 1569.

BENNETT, J. A. The challenge of practical mathematics. IN: PUMFREY, S.; ROSSI, P. L.; SLAWINSKI, M. (eds.). Science, Culture and Popular Belief in Renaissance Europe. Manchester/New York: Manchester University Press, 1991. p. 176-190.

BENNETT, J. A. Practical Geometry and Operative Knowledge. ConFigurations, Baltimore, v. 6, p. 195-222, 1998.

CAMEROTA, F. Misurare "per perspectiva": Geometria pratica e Prospectiva Pingendi. In: SINISGALLI, R. (ed.). La prospettiva: Fondamenti teorici ed esperienze Figurative dall'antichità al mondo moderno. Firenze: Edizioni Cadmo, 1998. 
CESANA, A. Textos e contextos dos problemas de medição de alturas em livros do Renascimento. 2013. 233 f. Tese (Doutorado em Educação) - Programa de Pós-Graduação em Educação, Universidade Federal do Espírito Santo, Vitória, Espírito Santo, 2013.

DIAS, M. S.; SAITO, F. Algumas potencialidades didáticas do "setor trigonal" na interface entre história e ensino de matemática. Educação Matemática Pesquisa, São Paulo, v. 16, n. 4, p. 1227-1253, 2014.

EUCLIDES. Ottica. Org. de F. Incardona. Roma: Di Renzo, 1996.

FABRI, Ottavio. L'Uso della squadra mobile. Padova: Pietro Bertelli, 1615.

HUGO DE SAN VITOR. Practical Geometry [Practica Geometriae] attributed to Hugh of St. Victor. Milwaukee, Wisconsin: Marquette University Press, 1991.

PANEPINTO, E. Ottavio Fabri, perito et ingegnero publico. Tese (Laurea Specialistica in Storia e Geografia dell'Europa - Indirizzo Geografico) - Facolta' di Lettere e Filosofia, Universita' Degli Studi di Verona, Verona, 2008, 2009.

SAITO, F. A reconstrução de antigos instrumentos matemáticos dirigida para formação de professores. Educação: Teoria e Prática, v. 29, n. 62, pp. 571-589, 2019.

SAITO, F. Algumas breves considerações sobre os tratados de geometria prática publicados no contexto do "saber-fazer" matemático quinhentista. IN: XII Seminário Nacional de História da Matemática. Anais, p. 271-277. São Paulo: SBHMat, 2018.

SAITO, F. Construindo interfaces entre história e ensino da matemática. Ensino da Matemática em Debate. São Paulo, v. 3, n. 1, pp. 3-19, 2016c.

SAITO, F. Desenhos e instrumentos de medida no processo de transmissão e de apropriação do conhecimento geométrico. IN: VÁSQUEZ, M. F.; CAPONI , S. ; SILVA, M. R. B. da (orgs.). 15 Seminário Nacional de História da Ciência e da Tecnologia. Anais, v. 1, p. 457-470. Rio de Janeiro: SBHC/UFSC, 2016a, 3 vols.

SAITO, F. História e ensino de matemática: construindo interfaces. IN: FLORES SALAZAR, J.; UGARTE GUERRA, F. (eds.). Investigaciones en Educación Matemática. Lima: Fondo Editorial PUCP, 2016b. p. 237-291.

SAITO, F. História da matemática e suas (re)construções contextuais. São Paulo: Ed. Livraria da Física/SBHMat, 2015.

SAITO, F.; DIAS, M. S. Articulação de entes matemáticos na construção e utilização de instrumento de medida do século XVI. Natal: SBHMat, 2011.

SAITO, F.; DIAS, M. S. Interface entre história da matemática e ensino: uma atividade desenvolvida com base num documento do século XVI. Ciência \& Educação, Bauru, v. 19, n. 1, pp. 89-111, 2013.

SAITO, F.; PEREIRA, A. C. C. A elaboração de atividades com um antigo instrumento matemático na interface entre história e ensino. São Paulo: Ed. Livraria da Física, 2019.

VILLARD DE HONNECOURT. Album de Villard de Honnecourt: Architecte du XIII e siècle. Manuscrit publiè en fac-simile. Ed. de J. B. A. Lassus. Paris: Imprimerie Impériale, 1858. 